\title{
ESCOLHA ENTRE ATRASOS E DURAÇÕES DIFERENTES DE REFORÇO: SOBRE A GENERALIZAÇÃO DE PREFERÊNCIAS EM TENTATIVAS DISCRETAS PARA UM PROCEDIMENTO DE OPERANTE LIVRE
}

\section{CHOICE BETWEEN DIFFERING DELAYS AND DURATIONS OF REINFORCEMENT: ON THE GENERALIZATION OF PREFERENCES IN DISCRETE-TRIALS TO A FREE-OPERANT PROCEDURE}

\author{
ELENice S. Hanna \\ UNIVERSIDADE DE BRASILIA, DF, BRASIL \\ AND \\ Derek E. Blackman \\ CARDIFF UNIVERSITY, WALES, UK
}

\begin{abstract}
RESUMO
Um procedimento de ajustamento do atraso de reforço foi utilizado para explorar pontos de indiferença com pombos no contexto de autocontrole e impulsividade. Doze pombos ingênuos foram inicialmente testados em um procedimento de tentativas discretas em caixas de condicionamento operante com três chaves de resposta por 40 ou 50 sessões. A décima resposta na chave central depois de uma bicada na chave esquerda era seguida, com um atraso de 4s, por 2-s de acesso a alimento, enquanto que a décima resposta na chave central depois de uma bicada na chave direita era seguida por um atraso ajustável e 4-s de acesso a alimento. O valor desse atraso era ajustado de acordo com as escolhas de cada sujeito permitindo-se estimar um ponto de indiferença ao longo das últimas 20 sessões como o valor do atraso que equilibrava os parâmetros fixos dos reforços. O atraso maior dos pontos de indiferença obtidos variou entre $9 \mathrm{~s} \mathrm{e} 17 \mathrm{~s}$. Os sujeitos foram então expostos a esquemas encadeados concorrentes semelhantes ao procedimento de tentativas discretas exceto que os elos iniciais consistiam de dois esquemas iguais de intervalos variáveis e o atraso que precedia o acesso a 4-s de alimento foi fixado para cada pássaro utilizando-se o valor calculado como seu ponto de indiferença da condição experimental anterior. Oito dos 12 pombos mostraram preferências consistentes por uma das chaves nos elos iniciais dos esquemas concorrentes. No presente estudo, portanto, o ponto de indiferença obtido no procedimento de tentativas discretas não se generalizou diretamente para o procedimento de esquemas concorrentes.

Palavras-chave: escolha, esquemas de reforçamento com parâmetro ajustável, procedimento de tentativas discretas, esquemas concorrentes encadeados, atraso de reforço, magnitude de reforço, autocontrole, bicar, pombos
\end{abstract}

\section{ABSTRACT}

An adjusting-delay procedure was used to explore points of indifference with pigeons in the context of self-control and impulsiveness. Twelve naive pigeons were first tested in this discrete-trials procedure in three-key operant conditioning chambers for 40 or 50 daily sessions. The 10th response on the central key after one peck on the left key was followed by 2 -s access to food $4 \mathrm{~s}$ delayed, while the 10th response on the central key after one peck on the right key was followed by an adjusting delay and 4-s access to food. The value of this delay was adjusted according to each subject's choices thereby allowing a point of indifference to be estimated over the last 20 sessions as the value of the delay conditions which balanced the fixed conditions. The longer delay of the indifference points ranged between $9 \mathrm{~s}$ and $17 \mathrm{~s}$. Subjects were then exposed to a concurrent-chains schedule similar to the discrete-trials procedure except that there were initial-links which consisted of equal and independent variable-interval schedules and the delay preceding 4-s access to food was fixed for each bird at the value calculated as its point of indifference from the previous experimental condition. Eight of the 12 birds showed consistent preference for one key in the initial links of the concurrent-chains schedules, suggesting that the point of indifference obtained from the discrete-trials procedure could not be generalized directly to the concurrent-chains procedure.

Key words: choice, adjusting schedules of reinforcement, discrete-trials procedure, concurrent-chains schedules, reinforcement delay, reinforcement magnitude, self-control, key-peck, pigeons 
Many investigators have examined choice between reinforcers differing in both delay and magnitude (see review by Logue, 1988). When subjects are allowed to choose between large, delayed reinforcers and smaller, more immediate reinforcers, self-control is defined as the preference for the larger, longer delayed reinforcer (LLR) over the smaller, shorter delayed reinforcer (SSR), whereas impulsiveness is the opposite (Ainslie, 1974; Navarick \& Fantino, 1976; Rachlin, 1974; Snyderman, 1983). Two kinds of situation have been used in these studies: a variety of discrete-trials procedures (e.g., Ainslie, 1974; Grosch \& Neuringer, 1981; Mazur \& Logue, 1978; Navarick, 1982), and free-operant procedures (e.g., Green \& Snyderman, 1980; Navarick \& Fantino, 1976; Rachlin \& Green, 1972; Snyderman, 1983). In discrete-trials procedures a single choice response leads to either LLR or SSR. In free-operant procedures, however, the choice period is usually programmed by means of equal intermittent schedules. Such a procedure was first used by Autor (1969) with two equal variable-interval schedules simultaneously and independently programmed for the choice period (termed initial links).

Free-operant procedures offer an advantage over those which require a single response in a quantitative analysis of choice. Intermittent reinforcement schedules programmed during the choice period tend to produce partial rather than all-or-none selection, whereas discrete trials usually result in exclusive preference for one alternative. Moreover, there are theoretical advantages in studying choices which are reinforced intermittently rather than continuously. If all behavior involves choice (Herrnstein, 1970; Mazur, 1986a) and "Relatively few classes of responses have consistent consequences" (Catania, 1984, p. 159), an understanding of performance on freeoperant schedules is essential to an understanding of behavior-environment interactions more generally.

On the other hand, studies of delayed consequences with discrete-trials procedures are easier to interpret. The choice period of these procedures is as brief as possible and so the actual delay between response and reinforcement is essentially the same as the scheduled delay. In free-operant procedures the length of the choice period serves as an additional delay that combines with the nominal delay (Mazur, 1987a), and such an additional delay contributes to determine the degree of preference for one alternative (Fantino, 1969; Mazur, 2002; Wardlaw \& Davison, 1974).

Thus the two procedures have strengths and weaknesses, but despite the differences outlined it is important to understand the extent to which results can be generalized from one procedure to another. A general formulation of choice behavior should account for performances on both.

Mazur (1984, 1985, 1986b, 1986c, 1987a, 1987b, 1988a, 1988b, 1989, 1991, 1992, 1995, 1996a, 1998a; see also Grossbard \& Mazur, 1986; Mazur \& Coe, 1987; Mazur \& Kralik, 1990; Mazur, Snyderman, $\&$ Coe, 1985) has published the results of several experiments using an adjusting discrete-trials procedure to explore effects on choice of various reinforcement parameters (e.g., delay, amount, probability). After an initial response on a central key, a pigeon's peck on one of two lateral keys is followed by a standard delayed presentation of food while a peck on the other lateral key is followed by an adjusting procedure in which food delays depend on previous choices. The adjusting-delay and durations of food values are manipulated in different conditions. This adjusting-delay procedure allows for identification of indifference points, defined as “.... pair of alternatives that a subject selects about equally often in a choice situation" (Mazur, 1988a, p.37). The indifference points obtained with such procedures are usually quite orderly, sufficient that simple equations (employing no free parameters) can account for about $90 \%$ of the variance across conditions (Mazur, 1984, 1986b).

The advantage of Mazur's procedure over other titration procedures such as those used by Logan (1965) and Navarick and Fantino (1972) is that reasonably accurate estimates of indifference points are found in considerably less time than would usually be required by 
those other methods which vary the delay after a number of sessions (Mazur, 1988a).

Mazur (1987a, Experiment 1) used the adjustingdelay procedure to identify indifference-point estimates between two different amounts of food (2 and 6 s) preceded by some delay. The delay for the shorter duration of food presentation was constant throughout conditions, and varied from 0 to $14 \mathrm{~s}$ across conditions. Results of individual birds showed initially fairly large fluctuations of mean adjusting delays in which a consistent choice of one reinforcer abruptly switched to a consistent choice of the other, but as the sessions continued the size of the fluctuations decreased, and the values of the mean delays became more stable (Mazur, 1987a). Estimates of the larger-reinforcer delays increased with increasing smallreinforcer delays. Indifference curves of the four birds showed delays of the large reinforcer approximately 2 to 3 times longer than those fixed for the smaller reinforcer with no bias towards one alternative.

Although it has long been recognized that the "value" or effectiveness of a reinforcer decreases with increasing delay, there has been no consensus about which mathematical expression best characterizes this relationship. (Mazur, 1987a, p. 57).

Using the adjusting-delay procedure, however, Mazur (1987a) was able to distinguish between several simple decay functions which relate reinforcer value to delay and magnitude of reinforcement (see also Rodriguez \& Logue, 1988). Equivalence rules between fixed and variable ratios and delays were well described by Mazur (1984, 1986b) and Mazur and Coe (1987), while investigations of similar parameters using concurrent schedules have suggested that fixed and variable schedules are not functionally equivalent in their effects upon choice (Navarick \& Fantino, 1972). Therefore, findings which would allow generalization of data from one procedure to another are a necessary step towards a general theory of choice. The experiment reported here was an attempt to assess the generality of the choice between LLR and SSR in discrete-trials and free-operant procedures.

In the present experiment an indifference point was identified for each subject using the adjusting-delay procedure and choice was then assessed in a subsequent concurrent-chains procedure with terminal-link delays based on the previously determined indifference points for each individual. If indifference points reflected estimates of equal distribution of responding, roughly equal relative response rates in the initial links of the concurrent-chains schedules would be expected since (a) the values of the parameters of reinforcement for each subject were defined on the basis of empirically derived indifference points, and (b) indifference of choice in concurrent-chains increases with longer initial links (Fantino, 1969; Wardlaw \& Davison, 1974).

In studies of choice between LLR and SSR individual differences "...seem to be the rule for both humans and nonhumans" (Mazur \& Logue, 1978, p. 16). Despite the emphasis on similarities, several studies have reported differences in response distribution between LLR and SSR across subjects (e.g., Ainslie, 1974; Mazur \& Logue, 1978; Rachlin \& Green, 1972). This variability makes the interpretation of results sometimes difficult and is an additional obstacle for quantitative analysis of choice and its environmental sources of control. Perhaps such variability derives from values of delays and magnitudes of reinforcer being arbitrarily defined. It is well known that preference in this choice situation depends on absolute and relative values of delays and magnitudes of reinforcer (e.g., Ainslie \& Herrnstein, 1981; Grace, 1994; Green \& Snyderman, 1980; Mazur, 2002, 2004; Navarick \& Fantino, 1976; Rachlin \& Green, 1972; Savastano \& Fantino, 1996; Snyderman, 1983). However some differences in preference between subjects are expected when they are tested with the same values of delays and magnitudes, as acknowledged by psychophysics experiments. Indeed the indifference points derived from the adjusting procedure vary between subjects (e.g., Mazur, 1986b, 1988a; Mazur et al., 1985). The adjusting-delay procedure used to identify indifference 
points between reinforcement delays and magnitudes is equivalent to a psychophysics procedure to identify threshold. Thus, the success of Mazur's studies in identifying equivalence between fixed and variable delays and ratios (Mazur, 1984, 1986b; Mazur \& Coe, 1987) may derive from a procedure in which the values of reinforcement dimensions are empirically defined for each subject's performance. Variability between subjects, which has discouraged quantitative analysis, has been found when these values are arbitrarily specified by the experimenter for all subjects in free-operant procedures (e.g., Navarick \& Fantino, 1972).

The free-operant concurrent-chains schedules used in the present experiment were programmed in a similar way to those procedures used by Dunn and Spetch (1990), Dunn, Williams and Royalty (1987), and Williams and Dunn (1991) in studies which examined the role of conditioned reinforcement in determining choice performance. The procedure has two important characteristics which are distinct from that used by Mazur (e.g., 1988a) or in other studies of choice between SSR and LLR.

First, choice responses were separated from responses which produced delayed reinforcement. Previous studies have shown that delay and magnitude of reinforcement affect response rates (e.g., Gentry \& Marr, 1980; Inman \& Cheney, 1974; Powell, 1969; Sizemore \& Lattal, 1978). As the choice contingency under investigation arranges alternatives which differ in both delays and magnitudes of reinforcement, it was thought to be important that the measure of choice was not confounded with the different rates of responding generated by different values of the reinforcement parameters, as suggested by Fantino (1977). Thus, after the choice period, delayed reinforcers followed responses under FR 10 schedules.

Second, choices in initial links and responses during the terminal links differ with respect to locus. Choice responses were made on the lateral keys and responses during the terminal links were made on the middle key. In the standard procedure, these responses differ with respect to the color on the keys: choice responses and responses during the terminal links are made on the lateral keys, and changes from initial to terminal links are signaled by changes on the key color. This procedure however has limitations for the study of choice. With initial- and terminal-link responses occurring on the same key, if the response pattern in the initial links is characterized by more than one response in quick succession, the first responses recorded for the terminal link may be the end of the initial-link response burst. In this case, the latency (or reaction time) and response rate in the terminal links are contaminated measures in the standard procedure, but not when responses during the terminal links are made on the middle key. The experiment reported below also therefore provides further empirical data with the modified procedure which can be compared with those obtained with Mazur's adjusting-delay procedure and with free-operant procedures more generally used in studies of choice with differing delays and magnitudes of reinforcement.

\section{METHOD}

\section{Subjects}

Twelve naive white pigeons served as subjects. The birds were maintained at approximately $80 \%$ of their freefeeding body weights by additional feeding, after the conclusion of the experimental sessions when necessary. The unusually large number of subjects used is due to the requirements of a group design in the research project of which this study was part.

\section{Apparatus}

Four three-response-key versions of the standard experimental chamber for operant conditioning studies with pigeons (Campden Instruments) were used, each housed in a sound attenuating box. The experiment was controlled and the data recorded in an adjacent room by online microcomputer (BBC-Master) programmed in 
SPIDER. Experimental sessions could be monitored through the video screen which showed each subject's recorded behavior and the number of obtained reinforcers.

\section{Procedure}

After shaping key pecking equally on each of the three keys, all subjects were exposed to a pre-training contingency. The pre-training consisted of two sessions with a complex contingency similar to that to which the subjects would be exposed during the first experimental condition. Both sessions lasted for 64 forced-trials. At the start of each trial one of the lateral keys was illuminated white. The order of presentation of right or left key varied randomly from trial to trial to prevent position preferences. A single peck on that key (CRF) darkened it and illuminated the central key white. The tenth response on the central key (FR 10) was followed by $3 \mathrm{~s}$ of food presentation $0.5 \mathrm{~s}$ delayed. A postreinforcement interval, when only the houselight was lit, then occurred followed by a 1-s blackout, so that the time from the peck on the lateral key to the beginning of the next trial was fixed (30 s). The white houselight was illuminated throughout the session except during reinforcement and blackout periods.

\section{Condition 1 - Adjusting-delay procedure}

The procedure used in this condition was derived from that used by Mazur (1988a) to estimate indifference points.

Each session lasted for 64 trials. The session was divided into 8 blocks of 8 consecutive trials, 2 forcedchoice and 6 free-choice trials. Figure 1 diagrams the sequence of events on a choice trial. At the start of a choice-trial both lateral keys were illuminated with white light, the houselight was on, and a single peck on one of the lit keys produced blackout on both lateral keys and white illumination on the middle key.

After pecking the left key, the tenth response on the middle key (FR 10) was followed by a 4-s delay during which only the houselight remained on. At the end of this standard delay, a 2-s reinforcement period began during which the houselight was extinguished and the light above the grain hopper was lit. After reinforcement, the houselight was again lit, and a postreinforcement interval began. The duration of the postreinforcement interval was such that the time from the choice peck to the next trial was fixed (30 s in the first 5 sessions and $40 \mathrm{~s}$ in the subsequent sessions).

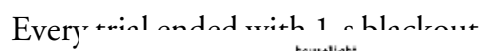

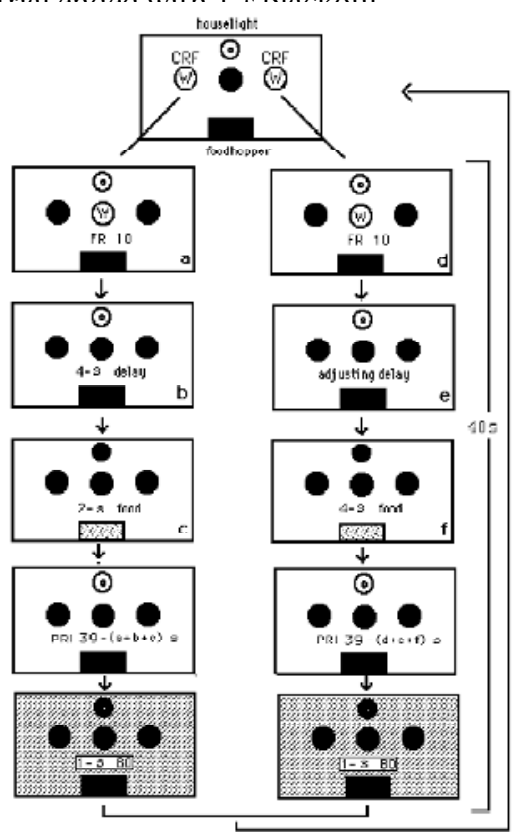

Figure 1 - Diagram of the adjusting-delay procedure.

If the right lateral key was pecked, the tenth response on the middle key was followed by an adjusting delay. The adjusting delay was followed by 4-s reinforcement period and then the postreinforcement interval. As with the 4-s delay with 2-s food, the time from a choice peck to the next trial was $40 \mathrm{~s}$ ( $30 \mathrm{~s}$ in first 5 sessions). Every trial ended with 1-s blackout. Note that the 30 -s or 40-s fixed terminal links were sustained regardless of the pigeons' behavior. Any segment of the terminal links (see Figure 1) not begun within 29 or 39 s was omitted, and any segment still in operation was ended, in both cases giving way to the 1-s blackout followed by the next trial. For example, if the periods of FR 10 (a or d), delay to food (b or e) and food ( $\mathrm{cor}$ f) totalled $29 \mathrm{~s}$ in the first five sessions 
or $39 \mathrm{~s}$ in subsequent sessions, the postreinforcement interval became zero, and the 1-s blackout was then immediately presented to end the trial. Thus a reinforcer could be "totally or partially missed" if the FR 10 requirement was not satisfied within a certain time (i.e., 23 or 33 s for 2 -s food, and 25 or 35 s minus the adjusting delay time for 4-s food). Misses or abbreviations of reinforcement such as this occurred very rarely in this experimental condition.

The procedure on forced-choice trials was the same as on free-choice trials except that only one lateral key was lit, and a peck on this key led to the appropriate delay after the tenth peck on the illuminated middle key. A peck on the alternate, darkened key had no effect. Of every two forced-choice trials, one involved the right key and the other the left key. The order of these two types of trials varied randomly.

After every 6 choice trials, the delay for the adjusting schedule might be changed. If a subject chose the adjusting delay with 4-s food more than three times, the delay was increased by $0.5 \mathrm{~s}$. If a subject chose the standard delay with 2-s food more than three times, the adjusting delay was decreased by $0.5 \mathrm{~s}$ unless it was already zero. If a subject chose each key three times, no change was made in the adjusting delay. In all three cases, the value of the adjusting delay remained in effect for the next block of 8 trials. At the start of the first two sessions of the experimental condition, the adjusting delay was set at $4 \mathrm{~s}$ for all subjects. At the start of every other session the adjusting delay was determined by the above rules as if it were a continuation of the preceding session.

The number of responses on each lateral key and the value of the adjusting delay were recorded for each of the 8 blocks of 8 trials in each session.

Although stability criteria used by Mazur were calculated for these data, these criteria were not used in the present experiment for reasons to be discussed later. The condition was terminated after 40 or 50 sessions, depending on visual inspection of the means of the adjusting delay for each 4 blocks (half-session) of the last
10 sessions. After 40 sessions, if there were still large fluctuations in the means of the adjusting delays (the difference between the highest and the lowest mean values was greater than $10 \mathrm{~s}$ ) or a systematic trend in the last 10 sessions, the subject was exposed to another 10 sessions (P12, P14, P19, P29, P33 and P34). If large fluctuations or a systematic trend occurred in those last 10 sessions as well, the subject was disqualified from the experiment.

In contrast to Mazur's procedures, the mean adjusting delay from the last 20 sessions (nearest integer value) was used as an estimate of the indifference point for each subject.

Two major modifications from Mazur's procedure were made in this experimental condition to approximate the contingency to more conventional concurrent-chains schedules. The first response was a choice response. Mazur's procedure requires one or more pecks on the centre key to begin the choice period. Secondly, the choice response in this experimental condition was followed by a second reinforcement schedule (FR 10) on the centre key, while in Mazur's procedure delayed reinforcement is the only programmed consequence of the choice response. Other differences between Mazur's and the present procedure were: (a) different colors on the keys and on the houselights were used by Mazur to signal the alternatives with different delays. In the present experiment, key side in the initial links was the unique discriminative stimulus; (b) to control for frequency both procedures fixed the period from the onset of the terminal link to the next trial. However, this period in Mazur's procedure included delay, reinforcement and intertrial interval and in the present experiment it also included time responding on FR schedule; and (c) 1-s blackout signaled the end of a trial in this condition.

\section{Condition 2 - Concurrent-chains schedules}

The pigeons were next transferred to a concurrentchains schedule (Autor, 1969) with two equal variableinterval 30-s schedules in the initial links and fixed-ratio 10 schedules in the terminal links. During the initial 
links, both lateral keys were illuminated white. Two independent timers were used to program the intervals for the variable-interval schedules in the initial links. Changeover responses were defined as the first peck on the right (or left) key preceded by a peck on the left (or right) key. A 2-s changeover delay (COD; Herrnstein, 1961) was in effect after each switching response, i.e., programmed reinforcement (entry to terminal link) was not delivered until a key peck occurred at least $2 \mathrm{~s}$ after a changeover response. When the terminal link became available to a peck on one side, the variable-interval timer associated with that side stopped while the alternate timer continued to operate. Entry into a terminal link stopped the alternate variable-interval timer and produced stimulus conditions appropriate to the terminal-link schedule: blackout on both lateral keys and white illumination on the middle key. The houselight remained on. Only the middle key was operative during the terminal link.

If the transition to a terminal link followed a peck on the left key, the tenth response on the middle key (FR 10) was followed by 4-s delay throughout the condition. During the delay period, only the houselight remained on. At the end of the 4-s delay, a 2-s reinforcement period began during which the houselight was extinguished and the light above the grain hopper was lit. After reinforcement, the houselight was again lit, initiating the postreinforcement interval. The duration of the terminal link was fixed at $30 \mathrm{~s}$ (instead of the 40-s trials in the earlier part of the study) to partially compensate for the longer initial link in condition 2 of the experiment. The postreinforcement interval completed the terminal-link duration. Every terminal link ended with 1-s blackout. Following this blackout the initial-link stimuli were reinstated and another cycle began.

If the transition to a terminal link followed a peck on the right key, both lateral-keys lights were extinguished and the tenth response on the middle key was followed by a longer delay. The value of the longer delay varied between subjects and was fixed for each bird at the value estimated as its point of indifference from the previous condition. The longer delay was followed by 4-s reinforcement period and then the postreinforcement interval. The 30-s fixed terminal links were sustained regardless of the pigeons' behavior. Any segment of the terminal links not begun within $29 \mathrm{~s}$ was omitted, and any segment still in operation was ended, in both cases giving way to the 1-s blackout followed by the next cycle. For example, if the periods of FR 10, delay to food and food totaled $29 \mathrm{~s}$, the postreinforcement interval became zero, and the 1-s blackout was then immediately presented to end the cycle. Thus, also in this condition, a reinforcer could be "totally or partially missed" if the FR 10 requirement was not satisfied within a certain time (i.e., $23 \mathrm{~s}$ for 2 -s food, and 25 or $35 \mathrm{~s}$ minus $\mathrm{x}$-s for 4-s food). Misses or abbreviations of reinforcement such as this occurred very rarely in this experimental condition.

The first session, but not subsequent sessions, began with two forced-choice cycles, one on each side, and then equal 15-s variable-interval schedules operated during the initial link for the rest of the session. In this first session, if a subject showed exclusive preference in the next 10 cycles, the 10 subsequent cycles were forced to the other side, with the preferred key dark and inoperative.

The concurrent-chains condition was terminated after 30 daily sessions. The number of responses on each key, the time spent responding on each key, and the number of changeovers in the initial links were recorded every session. Responses recorded as changeover responses were not included in the count of choice responses on that key. The number of entries to each terminal link and the time taken to complete the FR 10 requirement were also recorded.

\section{RESULTS}

Data from P33 were selected to illustrate why Mazur's stability criteria were not used in this study. To assess stability in the way used by Mazur (1988a), sessions were divided into two 32-trials blocks (half-session), and the mean delay on the adjusting key in each block was calculated. After session 16 data were considered stable: 
...when the following criteria were met, using data from subsequent sessions: (a) neither the highest nor the lowest single-block mean of a condition could occur in the last six blocks of the condition; (b) the mean adjusting delay across the last six blocks could not be the highest or the lowest sixblock mean of the condition; (c) the mean delay of the last six blocks could not differ from the mean of the preceding six blocks by more than $10 \%$ or by more than 1 -s (whichever was larger). (Mazur, 1988a, p. 39).

Figure 2 shows block-mean values of the adjusting delay during the adjusting delay condition. Vertical lines identify the six blocks which satisfied the criteria. Results of the adjusting-delay values of P33 showed fairly large fluctuations during the first 35 sessions in which a consistent choice of one terminal link abruptly switched to a consistent choice of the other. During the last 15 sessions, however, the size of the fluctuations decreased, and the mean delay of the large reinforcer became more stable. Extreme values of the delay occurred for the first time within the first 20 sessions. Stability according to Mazur's criteria was obtained frequently during the last 15 sessions. However, data from the six blocks from the second half of the 20th session satisfied the criteria as well. Such criteria were usually reached as a result of abrupt changes in the trend of the curve, i.e., when changes in preference occurred, once extreme values had occurred.

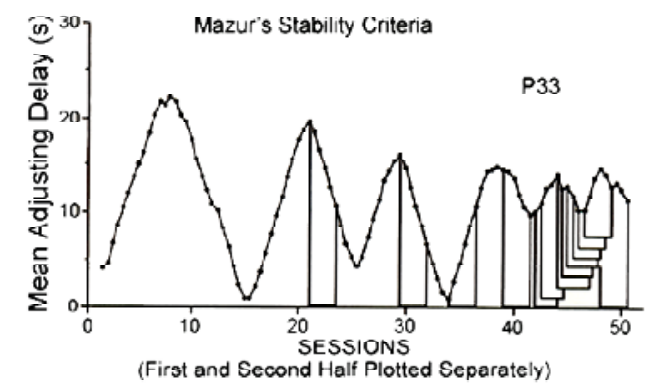

Figure 2 - Mean adjusting-delay in successive half-sessions of the discretetrials procedure over 50 sessions for subject P33. Data shown within vertical lines satisfied Mazur's stability criteria with the mean value of the adjusting-delays as shown.
This was the case for all subjects of the experiment, with the number of times and when the criteria were met dependent upon what session(s) extreme values of mean delays occurred.

Analyses of indifference estimates for each subject according to Mazur's stability criteria are presented in Table 1. The number of times that these criteria were met and the range of the estimates of indifference are presented in columns 2 and 3, respectively. The frequency of occurrence and the range of delay values when a criterion is added to those proposed by Mazur (1988a), i.e., criteria (a), (b) and (c) have to be met two or more consecutive times in succession, are presented in columns 4 and 5 . Stable performance according to Mazur's stability criteria was met by each subject a number of times during the exposure to the adjusting-delay procedure. Seven of the 12 subjects showed large differences $(5 \mathrm{~s})$ between the lowest and the highest estimates of indifference according to Mazur's criteria (column 3). The range of the estimates appears to be independent of the frequency with which the criteria were met. However when the criteria were met three or more times in succession the highest and lowest values of those delays (column 5) were very close, and usually differed by $1 \mathrm{~s}$, independently of the frequency of occurrence (column 4). From 12 subjects four however never met the criteria more than two times in succession.

The mean (used as estimate of indifference in this study), median and mode of values of adjusting delays of the last 40 half-sessions (last 20 sessions) are presented in columns 6 to 8 of Table 1. These measures were similar for each subject with differences between these descriptive values of $3 \mathrm{~s}$ or less for 10 of the 12 birds. The values of the estimates (mean) varied from 9 to $17 \mathrm{~s}$ between birds. Comparisons between the delay values presented in column 6 and those from column 3 show that the estimates of indifference adopted in this study (column 7) were within the range of the estimates given by Mazur's stability criteria (column 3). However the values of the delays used as indifference estimates in this study of only two of 
the subjects which met Mazur's criteria three or more times in succession (P13 and P26) were within the range of the mean-delay values shown in column 5 .

\section{Table 1}

Nearest integer values of the mean adjusting delays (in seconds). Number of times ( $\mathrm{col} 2$ ) Mazur's stability criteria were met during the adjusting delay condition and respective range of the indifference estimates ( $\mathrm{col} 3$ ). Number of times (col 4) Mazur's stability criteria were met consecutively and respective range of the indifference estimates ( $\mathrm{col} 5$ ). Mean ( $\mathrm{col}$ 6), Median (col 7) and Mode (col 8) of the half-session delays during the last 20 sessions. The mean were taken as estimates of indifference.

\begin{tabular}{|c|c|c|c|c|c|c|c|}
\hline \multirow[t]{3}{*}{ Subject } & \multicolumn{4}{|c|}{ Mazur's stability criteria } & \multicolumn{3}{|c|}{ Last 20 sessions } \\
\hline & \multicolumn{2}{|c|}{ overall } & \multicolumn{2}{|c|}{ consecutive times } & \multirow[b]{2}{*}{ Mean } & \multirow[b]{2}{*}{ Median } & \multirow[b]{2}{*}{ Mode } \\
\hline & $\mathrm{n}$ & range & $\mathrm{n}$ & range & & & \\
\hline P11 & 6 & $10-14$ & 4 & 13-14 & 10 & 11 & 14 \\
\hline P13 & 6 & $7-17$ & 3 & $11-12$ & 12 & 11.5 & 11 \\
\hline P14 & 6 & $6-10$ & - & - & 9 & 8 & 8 \\
\hline P18 & 9 & $8-16$ & 5 & $15-16$ & 13 & 15 & 15 \\
\hline P19 & 3 & $3-12$ & - & - & 11 & 11.5 & 14 \\
\hline P26 & 9 & $11-17$ & 8 & 17 & 17 & 17 & 17 \\
\hline P28 & 6 & $10-22$ & - & - & 12 & 11 & 11 \\
\hline P29 & 11 & $6-13$ & 3 & $6-7$ & 11 & 12 & 6 \\
\hline P30 & 17 & $14-15$ & 17 & $14-15$ & 12 & 13 & 13 \\
\hline P32 & 12 & $13-16$ & 8 & $15-16$ & 14 & 15 & 16 \\
\hline P33 & 13 & $6-16$ & 6 & $12-13$ & 11 & 12 & 13 \\
\hline P34 & 6 & $9-13$ & - & - & 11 & 11 & 12 \\
\hline 1 & 2 & 3 & 4 & 5 & 6 & 7 & 8 \\
\hline
\end{tabular}

The data of eight birds have been selected for the presentation of more detailed analyses. The effects illustrated are typical of all 12 birds and selection has been made solely to reduce space in this report. The constraints on choice of subjects for this more detailed presentation of results are that four birds (P14, P18, P32 and P34) showed approximate matching and four birds (P19, P26, P28 and P29) showed preferences in the subsequent concurrent-chains schedules. The bird whose data were selected for Figure 2 was not included in the eight. Figure 3 shows mean delays on the adjusting key in each half of the last 20 sessions of the adjustingdelay condition. This figure shows how mean delays in the sessions which were used to calculate the indifference point in the present study varied for each subject. The horizontal dashed line indicates the estimated value of indifference which is the mean of the data set. In general, mean delays used to estimate the indifference point for each subject include some degree of variability which decreased in the last 20 half-sessions. However, regardless of large fluctuations in the first 20 half-sessions, the estimates of indifference usually fell within the range of sections of small fluctuations.

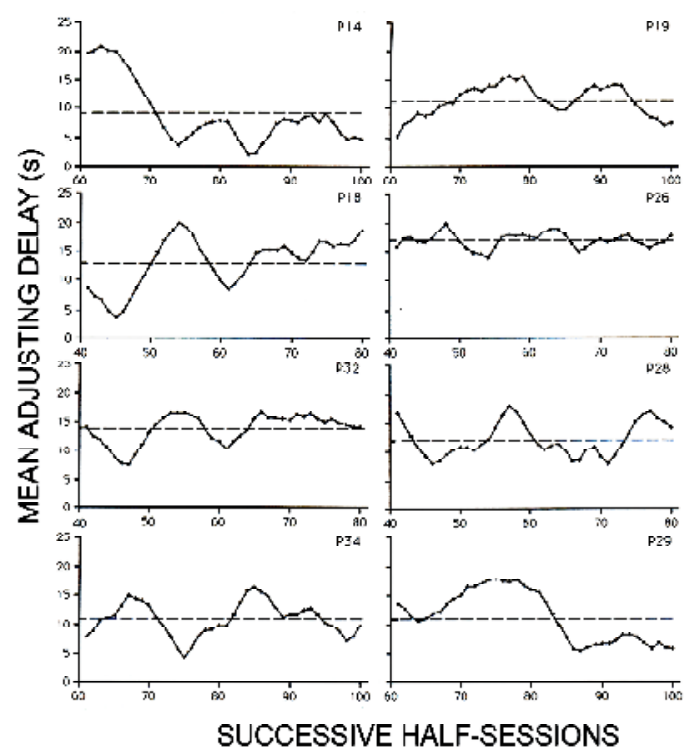

Figure 3 - Mean adjusting-delay in successive half-sessions of the last 20 sessions of the discrete-trials procedure, for eight subjects. The dashed line represents the mean of the values plotted.

Relative response rates (left key) during the initial links of the concurrent-chains condition for the first five and for the last five sessions are shown in Figure 4 for the same eight birds selected for the previous analyses. The dashed line indicates the point of indifference between the two terminal links. Eight of the 12 subjects showed a preference for the right key which led to the terminal link with LLR during the last five sessions (four of these subjects are presented on the right side of Figure 4), and four subjects showed indifference between alternatives (P14, P18, P32 and P34). Results of individual subjects show 
that whether approximate indifference $(0.60 \mathrm{e}$ " mean $\mathrm{e}$ 0.40 ) or preference for the right key (mean $>0.60$ ) was seen in the last five sessions, it developed during the training in the concurrent-chains condition and was not present in the first five sessions (see left side of each graph of Figure 4, except for P29 and P34), the data in the first five sessions being more variable within and between subjects.

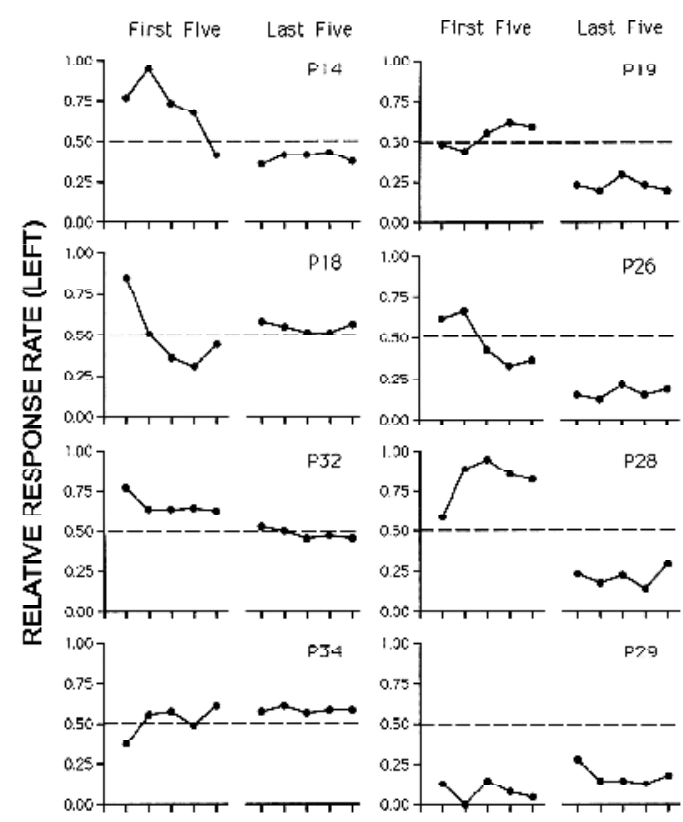

SESSIONS

Figure 4 - Relative response rates in the initial links of the concurrent-chains schedules for the first five and last five sessions for four subjects that showed approximately equal distribution of responses (graphs on the left) and four that showed preference for LLR (graphs on the right). The dashed line represents equal distribution of responses.

Figure 5 shows the mean total times in centiseconds to make the 10 responses required by the FR schedules from the onset of the terminal links (work time). Results of the last five sessions of Condition 2 for the SSR (filled symbols) and for the LLR (unfilled symbols) terminal links are presented separately for the same subjects selected for the previous analyses. In general subjects took between 2.5 and $8.0 \mathrm{~s}$ to fulfill the FR requirement. Seven of the 12 subjects showed consistently different FR-time in the LLR and SSR terminal links regardless of the equal discriminative stimuli for both terminal links. FR times were longer in the LLR terminal link for all seven subjects. T-tests of the work time in all cycles of the last five sessions showed that these differences were significant at the level of pe"0.05. Differences in work time for five subjects however were unsystematic and not significant.

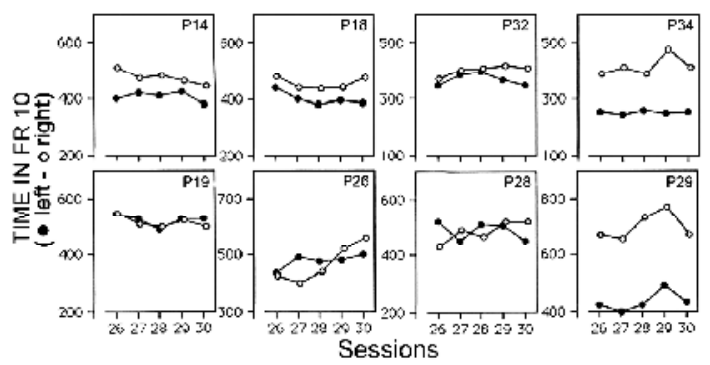

Figure 5 - Time from the onset of the terminal link to the tenth response on the centre key (work time) in centiseconds for the last five sessions of Condition 2 for eight subjects.

\section{DISCUSSION}

In the first part of the present study a discretetrials adjusting procedure was used similar to that which has been studied extensively by Mazur and his colleagues (Grossbard \& Mazur, 1986; Mazur, 1984, 1985, 1986b, 1986c, 1987a, 1987b, 1988a, 1988b, 1989, 1991, 1992, 1996a, 1996b, 1998a, 1998b; Mazur \& Coe, 1987; Mazur \& Kralik, 1990; Mazur et al., 1985). Delays to a larger reinforcement were adjusted as a function of pigeons' choices between the delayed large reinforcement and a smaller reinforcement which occurred after a fixed delay. Results showed that the adjusting procedure with FR 10 schedules in the terminal links and no differential stimuli signaling the two terminal links (but differential stimuli in the CRF initial links) gained control over behavior similarly to the procedure used by Mazur and colleagues. Similarly to Mazur's (1987a, 1988a) results, subjects in this experiment showed initially fairly large fluctuations of mean adjusting delays in which a consistent choice of one reinforcer abruptly switched to a consistent choice of the other, but as the sessions continued the size of the fluctuations decreased, and the values of the mean delays became more stable. Therefore the results extend 
Mazur (1987a, 1988a) to a different procedure with position rather than color as discriminative stimulus for the choice responses, the use of a FR 10 schedule on a middle key after a choice response, and no trial-initiation response.

The modified version of Mazur's procedure used in this study required about the same number of sessions for most subjects to reach these stability criteria but small variations of the adjusting delay began to occur after 30 sessions of training. Note however that Mazur and his colleagues (e.g., Mazur, 1986b, 1988a; Mazur \& Coe, 1987; Mazur et al., 1985) used subjects with extensive previous training and this study used naive subjects.

The mean adjusting delay over the last 20 of 40 or 50 sessions for each subject was taken as an estimate of indifference. These delay values were used subsequently as the combinations of delays and magnitudes of reinforcement in the terminal links of a concurrent-chains procedure with equal variable-interval schedules in the initial links. It was expected that subjects would show roughly equivalent relative rates in the longer choice period of the free-operant procedure since it has been found that choice tends toward indifference with longer initial links (Fantino, 1969; Mazur, 2002; Wardlaw \& Davison, 1974). However indifference estimates derived from the discrete-trials adjusting procedure tended to produce preference for the LLR when the reinforcement parameters were fixed in the procedure with longer initial links. The values of the large-reinforcer delay obtained in the adjusting-delay condition proved to be not sufficiently large to produce indifference in the concurrent-chains condition for nine of the 12 subjects, although the delay values were individually selected such that it was predicted that the birds would show no or little preference between them.

These results raise the question of whether indifference points were adequately defined in the adjusting delay condition. The stability criteria used by Mazur (1988a) were satisfied a number of times for all subjects (Table 1). However they were not used in the present study because these apparently demanding criteria proved not to be suitable in determining steady states of most subjects' behavior. The criteria were initially satisfied when there were still large systematic variations in the values of the adjusting delay, and did not predict well whether "stability" would be sustained (see Figure 3 and Table 1). The values of the mean adjusting delays were usually similar in two successive blocks of six half-sessions (see criterion " $c$ " in the results section) when abrupt changes of preference occurred. The stability criteria therefore were reached in these cases if the extreme delay values had occurred in previous sessions (as specified by criteria "a" and " $b$ "). However when these criteria were met two or more times in succession (criterion " $\mathrm{d}$ ") visual inspection confirmed small variations of the adjusting values. These analyses were presented in Table 1 together with analyses of the delay values used as estimates of indifference in this study. The mean delays over the last 20 sessions of six subjects were not within the range of the delay values which satisfied the four criteria (compare columns 6 and 5 of Table 1) and another four birds never met Mazur's criteria more than two times in succession. This could be taken as evidence that the mean delays used as indifference estimates failed to reflect subjects' stable preference during the adjusting-delay condition, and therefore the results of the second condition of the study are uninterpretable. However this argument is not sustained from the results of those two birds for which the delay values used in Condition 2 were identical to that found when Mazur's criteria were reached two or more consecutive times. Both P13 and P26 showed strong preference for the LLR.

In the present study, the indifference estimates were calculated as the mean adjusting delays over the last 20 sessions. These values ranged from $9 \mathrm{~s}$ to $17 \mathrm{~s}$ between subjects, and were regarded as the values of delay for 4-s food presentation which balanced the fixed alternative of 4-s delay for 2-s food presentation. The lack of individualized stability criteria for the calculation of points of indifference and as a basis for moving subjects from the discrete-trials procedure to the subsequent free-operant 
procedure may appear crude. However, the mean adjusting delays did not differ by more than $3 \mathrm{~s}$ from the median and mode values of the adjusting delay in 10 of the 12 subjects (Table 1 ). The generally small differences between these measures with individual birds suggest that the estimates of indifference points used in this study were reasonable reflections of most subjects' preference (see Figure 3) during the adjusting-delay condition. Further visual inspection of Figure 3 confirms that 40 or 50 sessions in the condition were sufficient to produce small variations in the adjusting delay values. In studies reported by Mazur (e.g., 1986b, 1988a) subjects reached the stability criteria approximately with 20 to 30 sessions in each condition.

It may be argued that preferences for the LLR showed by most subjects of this experiment (nine of 12) reflect bias towards the right key. Mazur (1984) showed that bias towards the adjusting-delay key is developed in adjusting delay procedures. To prevent such position preferences Mazur used color on the keys as the discriminative stimulus for the standard and adjusting delays. He usually varied randomly the left/right position of the red and green keys from trial to trial, thereby preventing position but not color bias. In this study, both lateral keys were illuminated white and pecks on the right key would lead to the adjusting link throughout the adjusting-delay condition. Therefore, perhaps preference for the right key showed by the majority of the subjects in the subsequent condition merely reflects bias gained during the previous condition. However, it should be noted that any bias contributed to the values of the indifference points calculated from data in the adjustingdelay condition and thus affected the values of the longer delay which were used in the concurrent-chains schedules. Moreover, preferences for the right key in the concurrentchains schedules were not marked in the first sessions of that procedure, but usually developed during the training in Condition 2 (see Figure 4), throughout which all parameters of reinforcement were fixed.

Results of the concurrent-chains schedules used in
Condition 2 show that the contingency exerted similar control over the behavior of eight of the 12 subjects. They all showed strong preference for the LLR. Results of those four birds (P14, P18, P32 and P34) which showed indifference between the alternatives should perhaps be considered as discordant. Equal distribution of responses may be derived from lack of control of the contingency of the terminal links with no differential stimulus. Results of responding in the terminal links (time in FR 10, Figure 5) however showed that the terminal links did produce differential responding with these birds. The time to make ten responses from the onset of the terminal link with the LLR was longer than the time to make ten responses from the onset of the terminal link with the SSR. Further, these results were similar to results of subjects which showed preference for the LLR terminal link and therefore suggest that the discriminative stimuli of the initial links (locus) associated with longer largereinforcement delay and shorter small-reinforcement delay were sufficient to produce differential behavior in the terminal links.

Thus points of indifference obtained from the discrete-trials adjusting procedure did not generalize in the form of indifference in the subsequent concurrentchains schedules. A number of procedural differences were incorporated in the experimental conditions. These include: a) adjusting variable parameters versus fixed parameters of reinforcement; $b$ ) continuous reinforcement versus variable-interval schedules during the choice phase; and c) the programming of a contingency for changeover responses (COD, Herrnstein, 1961) in the free-operant but not in the discrete-trials procedure. It would therefore be premature to draw conclusions about any general differences between discrete-trials and the more standard concurrent-chains schedules in terms of their effects on choice. A more definitive test should include individualized stability criteria to move subjects from one condition to another as well as to identify indifference estimates, and a condition between the adjusting-delay and concurrent-chains conditions to assess the adequacy 
of the indifference points estimates as well as to explore the parameters over which differences in discrete-trial and free-operant performance are evident. Further the crossmethod comparison would have greater generality if more conventional procedures were used, i.e., elimination of the FR 10 schedules in the terminal link and different discriminative stimuli for each terminal link. The results of the experiment should be interpreted however in the context of the orderliness of results from Mazur's adjusting procedure to establish the relationship between reinforcement value and delay which contrasts with the lack of consensus on the quantification of this relationship in studies with the more standard concurrent-chains schedules (e.g., Grace, 1994; Mazur, 2000, 2001, 2004; Navarick \& Fantino, 1972). Since the delay values of indifference from the adjusting procedure did not produce indifference in the free-operant procedure the present study suggests caution in attempting to incorporate findings which emerge from the two procedures in general theories of choice. It remains necessary to identify the conditions under which discrete-trial performance generalizes to concurrent-chains performance.

The present experiment succeeded in identifying values of a longer delayed reinforcement which produced similar preferences (for nine birds) in the concurrentchains schedule with VIs in the initial links, and showed that pigeons were sensitive to the terminal-link contingencies with identical discriminative stimuli (but different initial-link stimuli) programmed in the threekey concurrent-chains procedure.

\section{REFERENCES}

Ainslie, G.W. (1974). Impulse control in pigeons. Journal of the Experimental Analysis of Behavior, 21, 485-489.

Ainslie, G.W., \& Herrnstein, R.J. (1981). Preference reversal and delayed reinforcement. Animal Learning \& Behavior, 9, 476-482.

Autor, S.M. (1969). The strength of conditioned reinforcers as a function of frequency and probability of reinforcement. In D.P. Hendry (Ed.), Conditioned reinforcement, (pp. 127-162). Homewood, IL: Dorsey Press.
Catania, A.C. (1984). Learning. Englewood Cliffs, NJ: Prentice-Hall.

Dunn, R., \& Spetch, M.L. (1990). Choice with uncertain outcomes: Conditioned reinforcement effects. Journal of the Experimental Analysis of Behavior, 53, 201218.

Dunn, R., Williams, B.A., \& Royalty, P. (1987). Devaluation of stimuli contingent on choice: Evidence for conditioned reinforcement. Journal of the Experimental Analysis of Behavior, 48, 117-131.

Fantino, E. (1969). Choice and rate of reinforcement. Journal of the Experimental Analysis of Behavior, 12, 723 730.

Fantino, E. (1977). Conditioned reinforcement: Choice and information. In W.K. Honig, \& J.E.R. Staddon (Eds.). Handbook of operant behavior, (pp.313339). Englewood Cliffs, NJ: Prentice-Hall.

Gentry, G.D., \& Marr, M.J. (1980). Choice and reinforcement delay. Journal of the Experimental Analysis of Behavior, 33, 27-37.

Grace, R.C. (1994). A contextual model of concurrent-chains choice. Journal of the Experimental Analysis of Behavior, 61, 113-129.

Green, L., \& Snyderman, M. (1980). Choice between rewards differing in amount and delay: Toward a choice model of self control. Journal of the Experimental Analysis of Behavior, 34, 135-147.

Grosch, J., \& Neuringer, A. (1981). Self-control in pigeons under the Mischel paradigm. Journal of the Experimental Analysis of Behavior, 35, 3-21.

Grossbard, C.L., \& Mazur, J.E. (1986). A comparison of delays and ratio requirements in self-control choice. Journal of the Experimental Analysis of Behavior, 45, 305315.

Herrnstein, R.J. (1961). Relative and absolute strength of response as a function of frequency of reinforcement. Journal of the Experimental Analysis of Behavior, 4, 267-272.

Herrnstein, R.J. (1970). On the law of effect. Journal of the Experimental Analysis of Behavior, 13, 243-266.

Inman, D.P., \& Cheney, C.D. (1974). Functional variables in fixed ratio pausing with rabbits. The Psychological Record, 24, 193-202.

Logan, F.A. (1965). Decision making by rats: Delay versus amount of reward. Journal of Comparative and Physiological Psychology, 52, 1-12.

Logue, A.W. (1988). Research on self-control: An integrating framework. Behavioral and Brain Sciences, 11,665-709.

Mazur, J.E. (1984). Tests of an equivalence rule for fixed and variable reinforcer delays. Journal of Experimental Psychology: Animal Behavior Processes, 10, 426-436.

Mazur, J.E. (1985). Probability and delay of reinforcement as factors in discrete-trial choice. Journal of the Experimental Analysis of Behavior, 43, 341-351. 
Mazur, J. E. (1986a). Learning and behavior. Englewood Cliffs, NJ: Prentice-Hall.

Mazur, J.E. (1986b). Fixed and variable ratios and delays: Further tests of an equivalence rule. Journal of Experimental Psychology, 12, 116-124.

Mazur, J.E. (1986c). Choice between single and multiple delayed reinforcers. Journal of the Experimental Analysis of Behavior, 46, 67-77.

Mazur, J.E. (1987a). An adjusting procedure for studying delayed reinforcement. In M.L. Commons, J.E. Mazur, J.A. Nevin, \& H. Rachlin (Eds.), Quantitative analyses of behavior: Vol 5. The effect of delay and of intervening events on reinforcement value (pp.55-73). Hillsdale, NJ: Erlbaum.

Mazur, J.E. (1987b). Self-control choice with electrical stimulation of the brain as a reinforcer. Behavioural Processes, 15, 143-153.

Mazur, J.E. (1988a). Estimation of indifference points with an adjusting-delay procedure. Journal of the Experimental Analysis of Behavior, 49, 37-47.

Mazur, J.E. (1988b). Choice between small certain and large uncertain reinforcers. Animal Learning and Behavior, 16, 199-205.

Mazur, J.E. (1989). Theories of probabilistic reinforcement. Journal of the Experimental Analysis of Behavior, 51, 87-99.

Mazur, J.E. (1991). Choice with probabilistic reinforcement - effects of delay and conditioned reinforcers. Journal of the Experimental Analysis of Behavior, 55, 63-77.

Mazur, J.E. (1992). Choice with delayed and probabilistic reinforcers - effects of variability, time between trials, and conditioned reinforcers. Journal of the Experimental Analysis of Behavior, 58, 513-525.

Mazur, J.E. (1995). Conditioned reinforcement and choice with delayed and uncertain primary reinforcers. Journal of the Experimental Analysis of Behavior, 63, 139150.

Mazur, J.E. (1996a). Choice with certain and uncertain reinforcers in an adjusting-delay procedure. Journal of the Experimental Analysis of Behavior, 66, 6373.

Mazur, J.E. (1996b). Procrastination by pigeons: Preference for larger, more delayed work requirements. Journal of the Experimental Analysis of Behavior, 65, 159171.

Mazur, J.E. (1998a). Choice with delayed and probabilistic reinforcers: Effects of prereinforcer and postreinforcer stimuli. Journal of the Experimental Analysis of Behavior, 70, 253-265.

Mazur, J.E. (1998b). Procrastination by pigeons with fixed-interval response requirements. Journal of the Experimental Analysis of Behavior, 69, 185-197.

Mazur, J.E. (2000). Contextual choice and other models of preference. Behavioral and Brain Sciences, 23, 108-116.
Mazur, J.E. (2001). Hyperbolic value addition and general models of animal choice. Psychological Review, 108, 96-112.

Mazur, J.E. (2002). Evidence against a constantdifference effect in concurrent-chains schedules. Journal of the Experimental Analysis of Behavior, 77, 147155.

Mazur, J.E. (2004). Varying initial-link and terminallink durations in concurrent-chains schedules: A comparison of three models. Behavioural Processes, 66, 189-200.

Mazur, J.E., \& Coe, D. (1987). Tests of transitivity in choices between fixed and variable reinforcer delays. Journal of the Experimental Analysis of Behavior, 47, 287297.

Mazur, J.E., \& Kralik, J.D. (1990). Choice between delayed reinforcers and fixed-ratio schedules requiring forceful responding. Journal of the Experimental Analysis of Behavior, 53,175-187.

Mazur, J.E., \& Logue, A.W. (1978). Choice in a "self-control" paradigm: Effects of a fading procedure. Journal of the Experimental Analysis of Behavior, 30, 11 17.

Mazur, J.E., Snyderman, M., \& Coe, D. (1985). Influences of delay and rate of reinforcement on discretetrial choice. Journal of Experimental Psychology: Animal Behavior Processes, 11, 565-575.

Navarick, D.J. (1982). Negative reinforcement and choice in humans. Learning and Motivation, 13, 361377.

Navarick, D.J., \& Fantino, E. (1972). Transitivity as a property of choice. Journal of the Experimental Analysis of Behavior, 18, 389-401.

Navarick, D.J., \& Fantino, E. (1976). Self-control and general models of choice. Journal of Experimental Psychology: Animal Behavior Processes, 2, 75-87.

Powell, R. W. (1969). The effects of reinforcement magnitude upon responding under fixed-ratio schedules. Journal of the Experimental Analysis of Behavior, 12, 605608.

Rachlin, H. (1974). Self-control. Behaviorism, 2, 94-107.

Rachlin, H., \& Green, L. (1972). Commitment, choice and self-control. Journal of the Experimental Analysis of Behavior, 17, 15-22.

Rodriguez, M. L., \& Logue, A. W. (1988). Adjusting delay to reinforcement: Comparing choice in pigeons and humans. Journal of Experimental Psychology: Animal Behavior Processes, 14, 105-117.

Savastano, H.L., \& Fantino, E. (1996). Differences in delay, not ratios, control choices in concurrent chains. Journal of the Experimental Analysis of Behavior, 66, 97 116.

Sizemore, O. J., \& Lattal, K. A. (1978). Unsignalled delay of reinforcement in variable-interval schedules. Journal of the Experimental Analysis of Behavior, 30, 169- 
175.

Snyderman, M. (1983). Delay and amount of reward in a concurrent chain. Journal of the Experimental Analysis of Behavior, 39, 437-447.

Wardlaw, G.R., \& Davison, M.C. (1974). Preference for fixed-interval schedules: Effects of initial-link length.
Journal of the Experimental Analysis of Behavior, 21, 331340.

Williams, B. A., \& Dunn, R. (1991). Preference for conditioned reinforcement delay and conditioned reinforcement. Journal of the Experimental Analysis of Behavior, 55, 37-46. 